\title{
Effects of female diet and age on offspring sex ratio of the solitary parasitoid Pachycrepoideus vindemmiae (Rondani) (Hymenoptera, Pteromalidae)
}

\author{
Hao-Yuan Hu ${ }^{1,3}$, Zhong-Zheng Chen ${ }^{1}$, Bi-Sheng Duan ${ }^{1}$, Jin-Tu Zheng ${ }^{2} \&$ Tong-Xin Zhang ${ }^{2}$ \\ ${ }^{1}$ Key Laboratory of Biotic Environment and Ecological Safety in Anhui Province, College of Life Sciences, Anhui Normal University, Wuhu 241000, \\ China. \\ ${ }^{2}$ Ningbo Technology Extension Center for Forestry and Specialty Forest Products, Ningbo 315012, China. \\ ${ }^{3}$ Corresponding author. haoyuanhu@126.com
}

\begin{abstract}
Effects of female diet and age on offspring sex ratio of the solitary parasitoid Pachycrepoideus vindemmiae (Rondani) (Hymenoptera, Pteromalidae). Theories predict that females of parasitoid wasps would adjust the offspring sex ratio to environmental conditions in the oviposition patch, but the diet and age of females would also affect the sex ratio adjustment. Our focus was to test the effects of female diet and age on offspring sex ratio of the solitary parasitoid wasp, Pachycrepoideus vindemmiae (Rondani, 1875). Our results showed that females fed with honey had significantly less female biased offspring sex ratio than those fed only with water. Offspring sex ratio (male percentage) decreased with female age or female longevity at the beginning of oviposition but increased at the end. There should be a sperm limitation in $P$. vindemmiae females at the end of oviposition, and a higher frequency of unfertilized eggs were laid then. Females also laid more unfertilized eggs at the beginning of oviposition, which would be necessary to insure the mating among offspring. Male offspring developed faster and emerged earlier, which would also reduce the risk of virginity in offspring with female-biased sex ratio.
\end{abstract}

KEYWORDS. Behavior; Hymenoptera; host; parasitoid wasp; sex ratio adjustment.

RESUMO. Efeitos da dieta e idade da fêmea em relação à prole e à razão sexual do parasitoide solitário Pachycrepoideus vindemmiae (Rondani) (Hymenoptera, Pteromalidae). As teorias predizem que as fêmeas parasitoides de vespas ajustam a relação razão sexual dos descendentes, de acordo com condições ambientais, em cada oviposição. Entretanto, a dieta e idade das fêmeas também podem afetar o ajuste da razão sexual. Nosso foco foi testar os efeitos da dieta e idade da fêmeas em relação a razão sexual da prole da vespa parasitoide Pachycrepoideus vindemmiae (Rondani, 1875). Nossos resultados mostraram que as fêmeas alimentadas com mel apresentaram uma razão sexual significativa menor de fêmeas, do que aquelas alimentadas apenas com água. A razão sexual (percentagem dos machos) diminuiu com a idade ou longevidade das fêmeas no início da oviposição, mas com aumento no final. Deve haver uma limitação de esperma nas fêmeas de $P$. vindemmiae no final da oviposição e uma maior frequência de posturas de ovos infertilizados. As fêmeas também fazem posturas de um número maior de ovos infertilizados no início da oviposição, que seria necessário para assegurar o acasalamento entre os descendentes. A prole masculina desenvolverá mais rapidamente e emergirá mais cedo, o que também reduziria o risco de virgindade da prole, com a tendenciosa proporção de razão sexual maior das fêmeas.

PALAVRAS-CHAVE. Ajuste na proporção dos sexos; comportamento; hospedeiro, Hymenoptera, vespa parasitoide

Sex ratio adjustment has been taken as a model of sex ratio theory, and in many cases, sex allocation has been extremely successful, providing qualitative and even quantitative explanations of sex ratio variation (West 2009). In parasitic Hymenoptera, mated females store sperm in the spermatheca and can manipulate offspring sex ratio (males/ total offspring) by controlling fertilization during oviposition. The haplodiploid sex-determination system provides the mothers with a mechanism to control progeny sex ratio, because males develop from unfertilized eggs (haploid) and females from fertilized eggs (diploid) (Godfray 1994; Werren 1987). When mating takes place in small patches and involves mostly relatives, Theories predict that females are selected to maximize their fitness by producing few males, just the number necessary to guarantee all their daughters will be inseminated, and a female biased sex ratio will also bring less local mate competition (LMC) among the sibling male offspring (Hamilton 1967; Hu et al. 2010; West 2009). But reduce of males also increase the probability of virginity in offspring. Foundresses may reduce the risk by ensuring sufficient male offspring.

Evolutionary theories predict that parasitoid wasps should adjust the sex of their offspring according to varies of environmental conditions (West 2009), including resources (host and food) quality and abundance, such as host size (Charnov et al. 1981), host age (King 2000), host species (Uçkan \& Gülel 
2002), and host quality (healthy vs. parasitized) (van Baaren et al. 1999). Female characteristics, such as age and diet, also affect offspring sex ratio adjustment, but have been received less attention compared to host variables (SantolamazzaCarbone et al. 2007). Old females may have limited sperms in the spermatheca during oviposition. Sperm depletion or reduction in viability may lead offspring sex ratio increase (Santolamazza-Carbone et al. 2007).

Pachycrepoideus vindemmiae (Rondani, 1875) (Hymenoptera, Pteromalidae) is a cosmopolitan solitary ectoparasitoid, attacking pupae of a range of cyclorrhaphous dipteran species, such as Drosophila melanogaster Meigen, Ceratitis capitata Wiedemann, Rhagoletis sp., Delia radicum L., Fannia canicularis L., and Musca domestica L. (Rueda \& Axtell 1985), Cyrtoneurina pararescita Couri (Marchiori \& Silva Filho 2007), Megaselia scalaris (Marchiori \& Barbaresco 2007), Sarcodexia lambens Walker (Marchiori et al. 2003). The parasitoid has a peculiarity as a hyperparasitoid of dipteran and hymenopteran parasitoids (Wang \& Messing 2004), and also superparasitoidism when ovipositing in a single host (Tormos et al. 2009). In this article, we examined the effects of diet and age on $P$. vindemmiae offspring sex ratio.

Pachycrepoideus females are 2-3 mm long and produce one offspring per host, and hosts often occur in clumps. The parasitoid was obtained in the campus of Anhui Normal University, Wuhu, Anhui province, China, and was maintained using pupae of $M$. domestica $\mathrm{L}$ in glass vials $(25 \mathrm{~mm}$ in diameter by $50 \mathrm{~mm}$ in height) with $10 \%$ honey solution soaked cotton wool in an incubator at a light: dark photoperiod (14: 10). Temperature and relative humidity were $30 \pm 1{ }^{\circ} \mathrm{C}$ and $60 \pm 5 \%$, respectively. The given pupae were fresh housefly pupae (aged less than two days) and similar in size. The emerged offspring were collected together for about $24 \mathrm{~h}$ to ensure that females were mated.

Two treatments were designed to examine the effects of diet and age on offspring sex ratio, fed with honey or only water, respectively. A single mated female was daily given ten fresh housefly pupae. Honey soaked cotton wool was given daily in the vials in one treatment, and in the other treatment, only water was given in the cotton wool. Housefly pupae used in this experiment were all similar in size (length of the pupae were measured with a ruler to the nearest $0.5 \mathrm{~mm}$ ). The pupae taken out from the vials were respectively placed in other vials and reared till offspring emerged. The offspring were collected and the maturation time was recorded. In the treatments with honey and water, 19 and 32 groups were used, respectively.

The experiments were conducted under the photoperiod, temperature, and relative humidity conditions as above in an incubator. Pupae without houseflies emerged were dissected under a stereomicroscope to record the presence of uneclosed parasitoids. We recorded the sex of parasitoids from each pupa. Proportionally distributed data often have non-normally distributed errors and are thus difficult to analyze with traditional ANOVA techniques. To avoid these problems, we analyzed the sex ratio data using generalized linear model (GLM) analy- sis of deviance, assuming binomial errors, and a logit link function in R2.6.1 (Crawley 2007; Ihaka \& Gentleman 1996). The number of male wasps was used as the response variable, and the total offspring number was used as the binomial denominator. We checked the appropriateness of the assumption of binomial errors by comparing the residual deviance with the residual degrees of freedom after fitting the explanatory variables. Large relative values of the residual deviance indicate overdispersion, which may result in overestimation of significance levels, and binomial can be replaced with quasibinomial in the analyses. The minimal adequate model was tested using an $F$-test (Crawley 2007). Regression analyses and t tests of other data were finished in SPSS11.5.

Pachycrepoideus foundresses fed with honey had longer longevity and oviposition duration, and more female and male offspring than those fed only with water $\left(\mathrm{t}_{5.71}=18.15, \mathrm{t}_{4.83}=\right.$ $18.21, \mathrm{t}_{6.46}=19.25, \mathrm{t}_{3.16}=19.17$, respectively; all $\left.\mathrm{p}<0.005\right)$ (Table I). Offspring sex ratio of foundresses fed with honey was significantly more female biased $\left(\mathrm{F}_{1,910}=6.10, \mathrm{p}=0.014\right)$.

Table I. Longevity and offspring (means \pm SD) of Pachycrepoideus vindemmiae foundresses fed with honey or only water.

\begin{tabular}{lccccc}
\hline & Longevity & Oviposition duration & \multicolumn{3}{c}{ Offspring } \\
\cline { 4 - 6 } & $(\mathrm{d})$ & $(\mathrm{d})$ & Females & Males & Sex ratio \\
\hline \multirow{2}{*}{ Honey } & 11.89 & 9.53 & 26.84 & 6.89 & 0.20 \\
& $(6.99)^{*}$ & $(6.72)$ & $(13.76)$ & $(6.14)$ & $(0.12)$ \\
\multirow{5}{*}{ Water } & 2.72 & 2.06 & 6.09 & 2.38 & 0.29 \\
& $(0.58)$ & $(0.67)$ & $(3.32)$ & $(1.43)$ & $(0.15)$ \\
\hline
\end{tabular}

*Number in the parentheses means SD.

Male and female offspring number varied at different foundress longevity when fed with honey. Female offspring linearly increased with foundress longevity $\left(\mathrm{R}^{2}=0.72, \mathrm{p}<\right.$ 0.0001) (Fig. 1). Male offspring and sex ratio appear as a parabola with descending and ascending curves when foundress longevity is short and long $\left(\mathrm{R}^{2}=0.86, \mathrm{p}<0.0001\right.$; $\mathrm{R}^{2}=0.32, \mathrm{p}<0.01$; respectively). Female offspring linearly decreased with foundress age $\left(\mathrm{R}^{2}=0.16, \mathrm{p}<0.0001\right)$. Male offspring and sex ratio appears as a parabola with descending and ascending curves when foundress longevity is young and old $\left(\mathrm{R}^{2}=0.08, p=0.001 ; \mathrm{R}^{2}=0.12, \mathrm{p}=0.0001\right.$; respectively) (Fig. 2).

Total male and female offspring of the 19 females fed with honey were 131 and 510 respectively. Only one male offspring had a developmental duration at 13 days. There was significantly female biased sex ratio with the duration of development $\left(\mathrm{F}_{1,639}=10.47, \mathrm{p}=0.001\right)$. Male offspring had a shorter developmental duration $(15.65 \pm 1.86 \mathrm{~d})$ than female ones $(16.05 \pm 1.14 \mathrm{~d})\left(\mathrm{t}_{155.85}=2.35, \mathrm{p}=0.02\right)$. Offspring maturing lasted 8 days, but most offspring matured within 4 days $(96 \%, \mathrm{n}=641)$. Emergence order of male and female offspring differed. Significantly more male offspring emerged earlier $\left(F_{1,639}=4.49, p=0.034\right)$, especially on the first day during emergence, sex ratio was less female biased. 


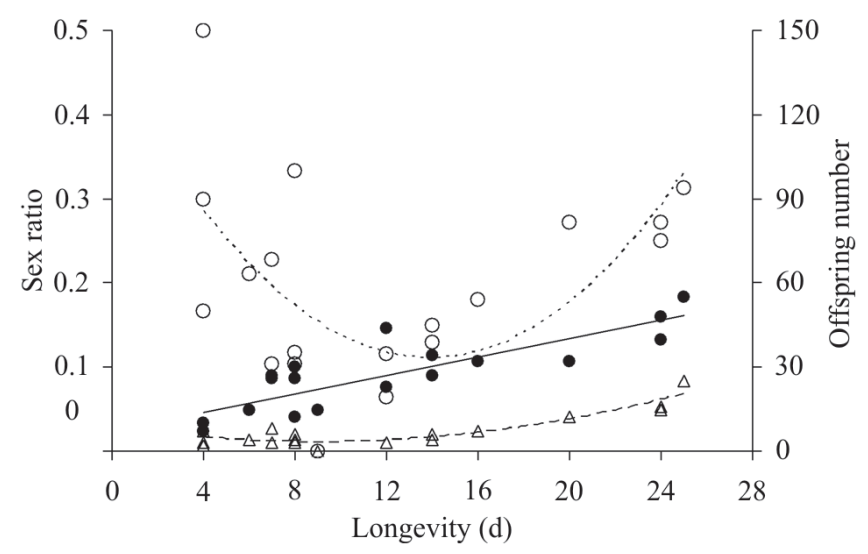

Fig. 1 Relationship between Pachycrepoideus vindemmiae longevity and male (triangle and dash line), female (black circle and solid line) offspring number, and offspring sex ratio (white circle and dotted line) respectively.
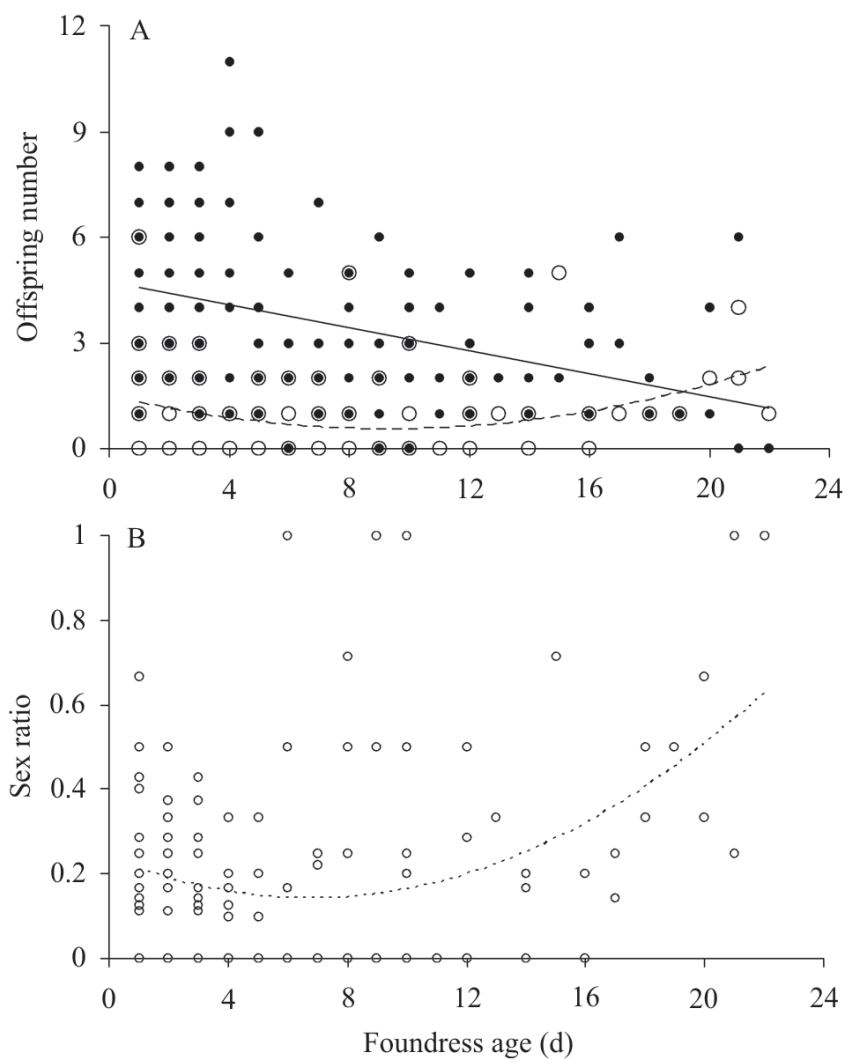

Fig. 2 Relationship between Pachycrepoideus vindemmiae age and male (dash line) and female (solid line) offspring number (A), and offspring sex ratio (dotted line) (B) respectively.

Pachycrepoideus foundresses fed with honey have significantly less female biased offspring sex ratio than only fed with water. Offspring sex ratio decreases with foundress age or longevity at the beginning of oviposition, but increases at the end of oviposition. Less female biased sex ratio is laid at the beginning of oviposition. The parasitoid wasps fed with only water have a shorter longevity, and only less female biased offspring have been laid. Therefore, they offspring sex ratio is less female biases than those fed with honey. Behav- ior of wasps is often interesting, and would help to control the pest insects (Torezan-Silingardi 2011). Parasitoid wasps such as $P$. vindemmiae often mate in the native patch, and mate soon after emergence (Bressac et al. 2008; Nadel \& Luck 1992). Mating often occurs between siblings. Therefore, female-biased sex ratio would benefit the foundresses because females are selected to maximize their fitness by producing few males, just the number necessary to guarantees all their daughters would be inseminated, and local mate competition (LMC) among the sibling male offspring would also be reduced (Hamilton 1967; Hu et al. 2010; West 2009). But reduce of males also increase the probability of virginity in offspring. Our results illuminate that female may reduce the risk by ensuring sufficient male offspring when emerge in a patch. Male offspring are laid earlier, develop faster than female ones, and emerge earlier during emergence.

When fig wasps and parasitoid wasps lay eggs in a patch, unfertilized eggs may be laid during the early duration of oviposition (Godfray 1994; Kjellberg et al. 2005; Moore et al. 2005; Raja et al. 2008). Such a 'male-first strategy' facilitates the production of optimal sex ratios by female parasitoids. If multifoundresses oviposit in a patch, there may be a reduction in clutch size per foundress because of limited oviposition sites in the patch (Moore et al. 2005; Raja et al. 2008). Higher proportion of male offspring means higher fitness to foundresses, because male offspring have the potential to mate with the female offspring of the other foundresses and the value of males increases (Hamilton 1967; Hu et al. 2010; West 2009). Therefore, to lay more unfertilized eggs at the beginning of oviposition should also bring a potential benefit to foundresses.

Sperm in the spermatheca of mated females should be limited at the end of oviposition, because the great majority of parasitic hymenoptera are often monandrous (King \& Bressac 2010). A solitary egg parasitoid, Uscana semifumipennis (Trichogrammatidae), has more male offspring with offspring fecundity, which indicates the sperm limitation when lay too many eggs (Henter 2004). Santolamazza-Carbone et al. (2007) also found old foundresses of a solitary egg parasitoid, Anaphes nitens (Mymaridae), have a more male biased offspring sex ratio because of sperm depletion, and they conclude that sex ratio is age dependent. In this article, $P$. vindemmiae foundresses lay less female biased sex ratio at the end of the oviposition, which indicates that there should also be a sperm limitation.

\section{ACKNOWLEDGMENTS}

We thank the anonymous reviewers, and Ji-Bing Liu and Zhang He for their help in the experiments. This project was supported by the National Science Foundation of China (31172145), Ph.D. Programs Foundation of Ministry of Education of China (20113424120005), the Key Foundation of Education Department of Anhui Province (KJ2011A133), the Innovation Funds of Anhui Normal University (2010cxjj13), and partially by Ningbo Science and Technology Bureau (No. 2009C10004). All experiments reported here comply with the current laws of China. 


\section{REFERENCES}

Bressac, C.; D. Damiens \& C. Chevrier. 2008. Sperm stock and mating of males in a parasitoid wasp. Journal of Experimental Zoology Part B 310: $160-166$

Charnov, E. L.; R. L. Los-den Hartogh; W. T. Jones \& J. van den Assem. 1981. Sex ratio evolution in a variable environment. Nature 289: 27-33.

Crawley, M. J. 2007. The R book. Chichester, John Wiley and Sons Ltd., viii $+942 \mathrm{p}$.

Godfray, H. C. J. 1994. Parasitoids: Behavioral and Evolutionary Ecology. Princeton, Princeton University Press, 473 p.

Hamilton, W. D. 1967. Extraordinary sex ratios. Science 156: 477-488.

Henter, H. J. 2004. Constrained sex allocation in a parasitoid due to variation in male quality. Journal of Evolutionary Biology 17: 886-896.

Hu, H. Y.; X. L. Zhu; Z. Z. Chen; L. M. Niu. \& Y. G. Fu. 2010. Sex allocation of parasitoid wasps. Chinese Bulletin Entomology 47: 1081-1088. (in Chinese with English summary).

Ihaka, R. \& R. Gentleman. 1996. R: a language for data analysis and graphics. Journal of Computational and Graphical Statistics 5: 299-314.

King, B. H. 2000. Sex ratio and oviposition responses to host age and the fitness consequences to mother and offspring in the parasitoid wasp Spalangia endius. Behavioral Ecology and Sociobiology 48: 316-320.

King, B. H. \& C. Bressac. 2010. No fitness consequence of experimentally induced polyandry in a monandrous wasp. Behaviour 147: 85-102.

Kjellberg, F.; J. L. Bronstein; G. van Ginkel; J. M. Greeff; J. C. Moore; N. Bossu-Dupriez; M. Chevolot \& G. Michaloud. 2005. Clutch size: a major sex ratio determinant in fig pollinating wasps? Comptes Rendus Biologies 328: 471-476.

Marchiori, C. H. \& L. F. Barbaresco. 2007. Occurrence of Pachycrepoideus vindemmiae (Rondani, 1875) (Hymenoptera: Pteromalidae) as a parasitoid of Megaselia scalaris (Loew, 1866) (Diptera: Phoridae) in Brazil. Brazilian Journal of Biology 67: 577-578.

Marchiori, C. H.; L. F. Pereira \& O. M. Silva Filho. 2003. Primeiro relato do parasitóide Pachycrepoideus vindemmiae (Rondani) (Hymenoptera: Pteromalidae) parasitando pupas de Sarcodexia lambens Wiedemann (Diptera: Sarcophagidae). Ciência Rural 33: 73-175.

Moore, J. C.; M. Zavodna; S. G. Compton \& P. M. Gilmartin. 2005. Sex ratio strategies and the evolution of cue use. Proceedings of the Royal Society B-Biological Sciences 272: 1287-1294.
Nadel, H. \& R. F. Luck. 1992. Dispersal and mating structure of a parasitoid with a female-biased sex ratio: implications for theory. Evolutionary Ecology 6: 270-278.

Marchiori, C. H. \& O. M. Silva Filho. 2007. New host for the parasitoid Pachycrepoideus vindemmiae (Rondani) (Hymenoptera: Pteromalidae) in Brazil. Arquivo Brasileiro de Medicina Veterinária e Zootecnia 59: 271-272.

Raja, S.; N. Suleman; S. G. Compton \& J. C. Moore. 2008. The mechanism of sex ratio adjustment in a pollinating fig wasp. Proceedings of the Royal Society B 275: 1603-1610.

Rueda, L. M. \& R. C. Axtell. 1985. Guide to common species of pupal parasites (Hymenoptera: Pteromalidae) of the house fly and other muscoid flies associated with poultry and livestock manure. North Carolina Agricultural Research Service Technical bulletin 278. North Carolina Agricultural Research Service, North Carolina State University, 1-88 p.

Santolamazza-Carbone, S.; M. P. Nieto \& A. C. Rivera. 2007. Maternal size and age affect offspring sex ratio in the solitary egg parasitoid Anaphes nitens. Entomologia Experimentalis et Applicata 125: 23-32.

Torezan-Silingardi, H. M. 2011. Predatory behavior of Pachodynerus brevithorax (Hymenoptera: Vespidae, Eumeninae) on endophytic herbivore beetles in the Brazilian tropical savanna. Sociobiology 57: 181-190.

Tormos, J.; F. Beitia; E. A. Böckmann; J. D. Asis \& S. Fernández. 2009. The preimaginal phases and development of Pachycrepoideus vindemmiae (Hymenoptera, Pteromalidae) on mediterranean fruit fly, Ceratitis capitata (Diptera, Tephritidae). Microscopy and Microanalysis 15: 422-434.

Uçkan, F. \& A. Gülel. 2002. Age-related fecundity and sex ratio variation in Apanteles galleriae (Hym., Braconidae) and host effect on fecundity and sex ratio of its hyperparasitoid Dibrachys boarmiae (Hym., Pteromalidae). Journal of Applied Entomology 126: 534-537.

van Baaren, J.; B. L. Landry \& G. Boivin. 1999. Sex allocation and larval competition in a superparasitizing solitary egg parasitoid: competing strategies for an optimal sex ratio. Functional Ecology 13: 66-71.

Wang, X. \& R. H. Messing. 2004. The ectoparasitic pupal parasitoid, Pachycrepoideus vindemmiae (Hymenoptera: Pteromalidae), attacks other primary tephritid fruit fly parasitoids: host expansion and potential non-target impact. Biological Control 31: 227-236.

Werren, J. H. 1987. Labile sex ratios in wasps and bees. BioScience 37: 498506.

West, S. A. 2009. Sex allocation. Princeton, Princeton University Press, 482 p.

Received 21/3/2011; accepted 28/5/2012

Editor: Kleber Del Claro 